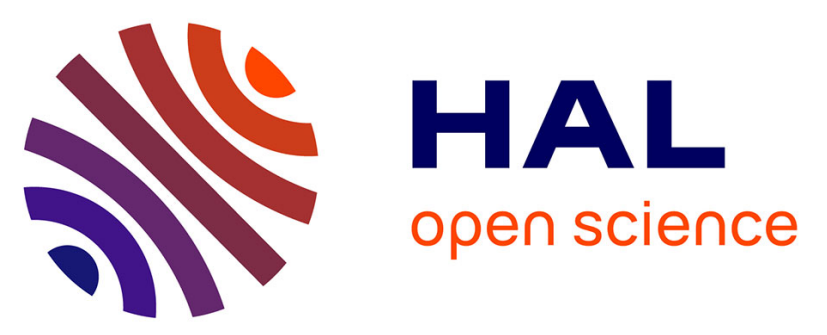

\title{
THE MEASUREMENT OF THE SINGLET OXYGEN YIELD IN THE REACTION OF THE CHLORINE WITH PEROXIDE CONTAINING COMPOUNDS
}

\author{
A. Dvoryankin, Yu. Kulagin, V. Yarygina
}

\section{- To cite this version:}

A. Dvoryankin, Yu. Kulagin, V. Yarygina. THE MEASUREMENT OF THE SINGLET OXYGEN YIELD IN THE REACTION OF THE CHLORINE WITH PEROXIDE CONTAINING COMPOUNDS. Journal de Physique IV Proceedings, 1991, 01 (C7), pp.C7-633-C7-635. 10.1051/jp4:19917170 . jpa-00250848

HAL Id: jpa-00250848 https://hal.science/jpa-00250848

Submitted on 1 Jan 1991

HAL is a multi-disciplinary open access archive for the deposit and dissemination of scientific research documents, whether they are published or not. The documents may come from teaching and research institutions in France or abroad, or from public or private research centers.
L'archive ouverte pluridisciplinaire HAL, est destinée au dépôt et à la diffusion de documents scientifiques de niveau recherche, publiés ou non, émanant des établissements d'enseignement et de recherche français ou étrangers, des laboratoires publics ou privés. 


\title{
THE MEASUREMENT OF THE SINGLET OXYGEN YIELD IN THE REACTION OF THE CHLORINE WITH PEROXIDE CONTAINING COMPOUNDS
}

\author{
A.N. DVORYANKIN, Yu.A. KULAGIN and V.N. YARYGINA \\ Department of Optics, P.N. Lebedev Physical Institute, Leninsky Prospekt, Moscow 117924, \\ USSR
}

\begin{abstract}
The use - of solid compounds for the singlet oxygen (SO) generator was investigated. $\mathrm{By}$ the means of combined calorimetric and luminescence method were investigated the reactions of gaseous chlorine with different peroxide-containing compounds. The quantitative measurements of the $\mathrm{SO}$ yield was done and it was close to unity both for the alkaline peroxide and for the solid peroxide - containing compounds. Comparing with peroxide solution, the solid compounds have the following vantages: they are easier for use, they have greater $\mathrm{SO}$ yield from the unit mass of reagents and water vapor concentration at the outlet of the $\mathrm{SO}$ generator is minimal.
\end{abstract}

Today the power of Chemical Oxygen-Iodine Laser (COIL) and it efficiency is determined mainly by the operational characteristics of the Singlet Oxygen Generator (SOG) $[1,2]$.

The known COIL work with liquid SOG, in which Singlet Oxygen (SO) is generated as the result of interaction of alkaline-peroxide water solution with gaseous chlorine. The chemical reaction occurs on the gas/liquid interface and is limited by the interface area, so in such SOG it is difficult to achieve high pressure and yield of SO.The gas flow after these generators contains high concentration of water vapor, which makes the operational characteristics of COIL worse [3].

The alkaline-peroxide solution can't be stored ready for use.So complicated mixing, transport and freezing systems are necessary for the liquid SOG operation. These shortcomings are the main factor, which limits the power of COIL and it's use as technological laser.

It is possible to achieve sufficient in crease in SOG productivity as the result of changing alkaline peroxide solution by solid peroxide - containing compounds.

Peroxihydrates of inorganic salts can be stored ready for use. For our investigations peroxihydrates of weak acid and strong base were chosen. This solution has alkaline reaction. As a result of such salt hydrolysis the alkaline solution of hydrogen peroxide is obtained. In the reaction of such solution with chlorine $\mathrm{O} 2(\mathrm{a})$ is released. In the reaction of chlorine with solid peroxihydrates the reaction begins on the surface of solid compounds as a result of small water concentrations containing in SOG. Later in hydrolysis partisipates water, which is released in $\mathrm{H}_{2} \mathrm{O}_{2}$ decomposition.

The aim of our investigation was the quantitative measurement of $\mathrm{SO}$ yield while the interaction of chlorine with different peroxihydrate: compounds and the proof of the possibility of SO generation using these compounds in sufficient quantity for the COIL operation.

To measure the concentration of $\mathrm{SO}$ the combined calorimetric and luminescence method was used. For different temperatures of platinum wire of the calorimeter simultaneously was measured the energy rolease on the wire as a result of $\mathrm{O} 2(\mathrm{a})$ quenching and the intensity of $\mathrm{O} 2(\mathrm{a})$ luminescence after the calorimeter. The probability of $\mathrm{O} 2(\mathrm{a})$ quenching on the platinum surface depends significantly on the wires temperature. So the heat release on the calorimeter is inversely proportional to the intensity of $\mathrm{O} 2(\mathrm{a})$ luminescence after the calorimeter. So the calibration of the results of optical measurement can be done. 
The measurements were done on the vacuum device which was equipped by a model SOG, system of $02(\mathrm{a})$ luminescence registration and a calorimeter. The.SOG was a glass tube with $4 \mathrm{sm}$ diameter and $20 \mathrm{sm}$ length. It was divided by a glass plate with $100-150 \mathrm{mcm}$ holes. Through these holes the gas was supplied. The $\mathrm{O} 2$ (a) luminescence was measured by photo multiplier with photo cathode, which was cooled by liquid nitrogen vapor.

The SOG was fitted by the peroxihydrates power. The chlorine was supplied through the holes in the glass plate. The intensive dimole $(\lambda=634,703 \mathrm{~nm})$ in the visible band and $\mathrm{IR}(\lambda=1,27 \mathrm{mcm})$ luminescence was measured while the interaction of the chlorine with peroxihydrates powders. The temporal dependence of $\mathrm{O} 2(\mathrm{a})$ luminescence while the reaction of $\mathrm{Na}_{3} \mathrm{PO}_{4} \cdot 5 \mathrm{H}_{2} \mathrm{O}_{2} \cdot 2 \mathrm{H}_{2} \mathrm{O}$ with chlorine (reduced to the total $\mathrm{O} 2$ yield (1)) is plotted on Fig.1. Line (2) is the same dependence for liquid SOG. The most intensive O2(a) release for the solid compounds SOG is at the first stage, when chlorine interact with peroxihydrate powder in pseudo-liquid state. Later a sufficient quantity of water is released, the power is wetted and its particles stick together. As a result the rate of O2(a) release decrease rapidly.

Because of non-stationary character of $\mathrm{SO}$ release the averaged concentration of $\mathrm{O}(\mathrm{a})$ in the gas flow was measured. The integral intensity of $\mathrm{O}_{2}(\mathrm{a})$ luminescence $(\lambda=1,27 \mathrm{mcm}$ was measured during the total time of the SOG operation. The concentration of O2(a) in the flow was measured as a result of calibration of optical registration system using calorimetric method $/ 4 /$. The total quantity of the released oxygen was estimated using the Peroxihydrates salt expenditure. This gives the upper value of $\mathrm{O}_{2}$ in the flow and consequently the lower value of $\mathrm{Z}=\mathrm{O}_{2}(\mathrm{a}) / \mathrm{O}_{2}$ which is the main characteristic of the SOG efficiency.

In Tabl.1 the results of quantitative measurement of $\mathrm{O} 2(\mathrm{a})$ release in reactions of the chlorine with different peroxihydrates compounds are plotted. The experimental results show that almost all $\mathrm{O}_{2}$ molecules are released in the exited state $\mathrm{O}_{2}(\mathrm{a})$ in the reaction of the chlorine with peroxihydrates as in reaction with liquid alkaline peroxide solution. Our experimental results for liquid SOG are confirmed by other investigators $/ 4,5 /$. This shows the reliability of our results. So the high efficiency of solid compounds for SO generation is proved. The development of SOG with solid compounds can sufficiently simplify their construction and improve their operational characteristics reduced to the mass of reagents.

Tabl.1 O2(a) yield reduced to the weight of reagents for different solid compounds and peroxide solution.

\begin{tabular}{lcccc}
\hline Compound & $\begin{array}{c}\text { Weight of } \\
\text { sample } \mathrm{g}\end{array}$ & $\begin{array}{c}\text { reduced } \\
\text { yield a.u }\end{array}$ & $\begin{array}{c}\text { operation } \\
\text { time (min) }\end{array}$ & $\mathrm{Z}$ \\
\hline $\mathrm{Na}_{3} \mathrm{PO}_{4} \cdot 5 \mathrm{H}_{2} \mathrm{O}_{2} \cdot 2 \mathrm{H}_{2} \mathrm{O}$ & 3 & 71 & 20 & 0.55 \\
& 2 & 93 & 15 & 0.65 \\
& 1 & 94 & 10 & 0.63 \\
& 0.5 & 96 & 8 & 0.60 \\
$\mathrm{~K}_{3} \mathrm{PO}_{4} \cdot 4 \mathrm{H}_{2} \mathrm{O}_{2} \cdot \mathrm{mH}_{2} \mathrm{O}$ & 1 & 89 & 11 & 0.53 \\
$\mathrm{~K}_{3} \mathrm{CO}_{3} \cdot 2 \mathrm{H}_{2} \mathrm{O}_{2} \cdot \mathrm{m}_{2} \mathrm{O}$ & 2 & 50 & 18 & 0.50 \\
$\mathrm{H}_{2} \mathrm{O}_{2}+\mathrm{NaOH}_{2} \mathrm{H}_{2} \mathrm{O}$ & 9.8 & 35 & 14 & 0.6 \\
6
\end{tabular}

$6 \mathrm{~N}$ solution

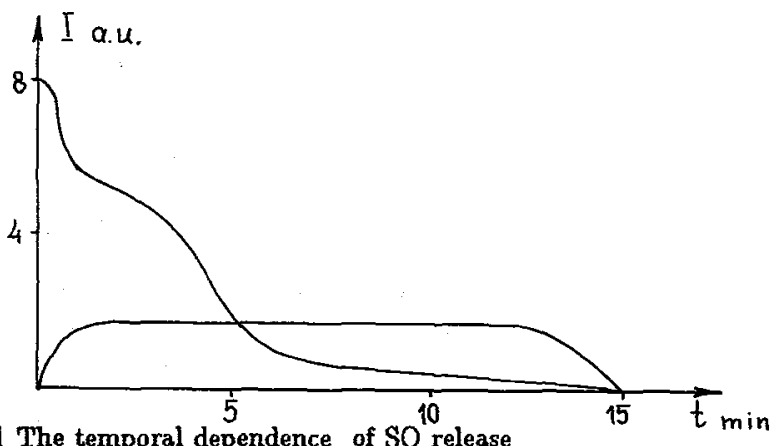

Fig.1 The temporal dependence of $\mathrm{SO}$ release 


\section{References}

1.Didukov A.I., etcet.Kvant.Elektr.(Sov.)16(1989),892.

2.Didukav A.I., etcet.Kvant.Elektr.(Sov.), $9(1982), 731$.

3.Didukov A.I., etcet.FIAN Proc.144(1984)1208.

4.Bitieva I.N., Tchernikov V.S. J.Chem.Phys.(Sov.)18(1989)1208

5.Bitieva I.N., Prepr. FIAN N176 